
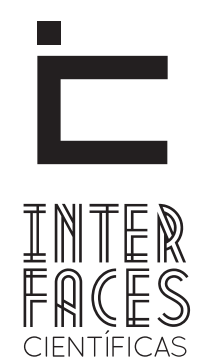

DIREITO

ISSN IMPRESSO 2316-3321

E-ISSN 2316-381X

DOI 10.17564/2316-381X.2016v4n2p79-92

\title{
DIREITO AO ESQUECIMENTO COMO DIREITO DA PERSONALIDADE VERSUS LIBERDADE DE EXPRESSÃO COMO DIREITO À INFORMAÇÃO: PONDERAÇ̃̃O ENTRE DIREITOS FUNDAMENTAIS COM A APLICAÇÃO DA PROPORCIONALIDADE E RAZOABILIDADE \\ RIGHT TO OBLIVION AS PERSONALITY RIGHTVERSUSFREEDOM OF EXPRESSIONAS RIGHT TO INFORMATION: FUNDAMENTALS \\ WEIGHTING BETWEEN FUNDAMENTAL RIGHTS WITH APPLICATION OF PROPORTIONALITY AND REASONABILITY DERECHO AL OLVIDO COMO DERECHO DE PERSONALIDAD VERSUS LA LIBERTAD DE EXPRESIÓN COMO DERECHO A LA INFORMACIÓN: EQUILIBRIO ENTRE LOS DERECHOS FUNDAMENTALES DE LA APLICACIÓN PROPORCIONALIDAD Y RAZONABILIDAD
}

\section{RESUMO}

Os avanços tecnológicos ocorridos nos dois últimos séculos conduzem para a construção de uma nova sociedade, cujas divisões entre o público e o privado, quando relacionados à vida humana, parecem desaparecer. Os atuais meios de comunicação, mais rápidos, seguros e eficientes, de acesso e alcance mundiais, de fato potencializaram as relações pessoais e comerciais, constituindo indispensável fonte de desenvolvimento humano. Entretanto, o que se experimenta, também, é a utilização desses meios de forma abusiva ou ilícita, capaz de atingir até mesmo os direitos de ordem fundamental. A internet, indiscutível ferramenta de interação comunicativa, não possui barreiras físicas, temporais ou espaciais, sendo capaz de gerir dados, armazená-
- los eternamente, e direcioná-los a todo o mundo. Neste contexto, o direito ao esquecimento surge como um instrumento de controle da utilização de informações que são alvo de nova exploração, seja por profissionais do jornalismo ou internautas. O presente trabalho busca definir e explorar as principais vertentes do direito ao esquecimento, recentemente reconhecido no Brasil como direito da personalidade, abordando seus aspectos relevantes e sua importância no cenário jurídico atual. 0 grande desafio da introdução do direito ao esquecimento em nosso ordenamento pátrio, contudo, é garantir que sua aplicação não se constitua em censura, uma vez que confronta diretamente direitos como a liberdade de expressão e comunicação. 


\section{PALAVRAS-CHAVE}

Fundamentais. Esquecimento. Comunicação.

\section{ABSTRACT}

Technological advances in the last two centuries lead to the construction of a new society, whose divisions between public and private, when they are relate to human life, seem to disappear. Today's media, with a faster, safer, more efficient access and global reach, actually potentiated personal and business relationships, providing indispensable source of human development. However, what is experienced is also the use of these means of improper or unlawful manner, able to reach even the fundamental rights of order. The internet, indisputable tool of globalization and knowledge, has no physical, temporal or spatial barriers, being able to manage data, store them forever, and directs them to the whole world. In this context, the right to oblivion emerges as an instrument to control the use of information that is the subject of new ex-

\section{RESUMEN}

Los avances tecnológicos en los últimos dos siglos conducen a la construcción de una nueva sociedad cuyas divisiones entre lo público y lo privado, cuando se relaciona con la vida humana, parecen desaparecer. Los medios de comunicación de hoy en día, el acceso más rápido, seguro y eficiente y el alcance global, en realidad potenciaron las relaciones personales y comerciales, que constituyen fuente indispensable del desarrollo humano. Sin embargo, lo que se experimenta es también el uso de estos medios de manera abusiva o ilegal, capaces de llegar hasta el fin de los derechos fundamentales. El Internet, indiscutible herramienta de comunicación interactiva, no tiene barreras físicas, temporales o espaciales, siendo capaz de gestionar los datos, almace- ploration, whether by professional journalists or users of internet. This study aims to define and explore key aspects of the right to be forgotten, recently recognized in Brazil as a right of personality, addressing material respects and its importance in the current legal scenario. The great challenge of the introduction of the right to oblivion in our paternal system, however, is to ensure that your application does not constitute in censorship, as it directly confronts rights such as freedom of expression and communication.

\section{KEYWORDS}

Fundamental Rights. Oblivion. Communication.

narlos eternamente, y dirigirlos a todo el mundo. En este contexto, el derecho al olvido surge como un instrumento de control del uso de la información que es objeto de nuevas exploraciones, ya sea por periodistas profesionales o usuarios de Internet. Este estudio tiene como objetivo definir y explorar aspectos clave del derecho a ser olvidado, recientemente reconocida en Brasil como un derecho de la personalidad, abordando los aspectos materiales y su importancia en el escenario jurídico actual. El gran reto de la introducción del derecho a ser olvidado en nuestro ordenamiento jurídico patrio, sin embargo, es asegurarse de que su solicitud no constituye en censura, ya que se enfrenta directamente a los derechos como la libertad de expresión y de comunicación. 


\section{PALABRAS-CLAVE}

Derechos Fundamentales. Olvido. Comunicación.

\section{INTRODUÇ̄̃O}

A evolução dos meios de comunicação, principalmente com a criação da internet, propõe à sociedade atual um novo paradigma de globalização, capaz de transpor quaisquer barreiras. Entretanto, a má utilização destes meios vem provocando sérios prejuízos aos direitos fundamentais que não podem ser ignorados pelo Direito. Neste cenário surge o direito ao esquecimento, que possibilita a discussão acerca do uso indeterminado de fatos que prejudica os envolvidos após anos de seu acontecimento.

0 direito ao esquecimento foi reconhecido no direito brasileiro há pouco tempo, já ganhando status de direito da personalidade, porém os estudos e pesquisas sobre o tema ainda são ínfimos. Com isso, o presente estudo teve o ímpeto de buscar a origem e as diretrizes deste direito, pontuando suas principais vertentes e apresentando-a ao mundo acadêmico, buscando estabelecer seu papel na atual sociedade da informação que nos cerca.

Mesmo quando entendemos a ideia central do direito ao esquecimento, que tem origem na esfera criminal, automaticamente somos invadidos por uma série de indagações sobre o tema, como por exemplo: o direito ao esquecimento pode ser aplicado na esfera cível? Ao limitar a atuação dos meios de comunicação, não seria uma forma revestida de censura ou um meio de se apagar a própria história? É possível aplicar com efetividade o direito ao esquecimento no ambiente da internet?

Tais indagações surgem basicamente pela prematuridade do tema no país, sendo esta a principal justificativa para o desenvolvimento deste artigo.
Com a exposição e aprimoramento deste tema, podemos utilizá-lo como instrumento de proteção da dignidade humana.

Em se tratando de um tema, como chamamos, recém-chegado, não existe farto arcabouço bibliográfico sobre ele. Assim, o estudo teve como fontes básicas de pesquisa a análise de decisões judiciais, tanto estrangeiras quanto nacionais. No Brasil, as principais ferramentas são o Enunciado n 531 da VI Jornada de Direito Civil, realizada em março de 2013 e dois julgamentos do Superior Tribunal de Justiça de maio de 2013, que reconheceram a aplicação do direito ao esquecimento em nosso ordenamento jurídico.

Por esta razão o tema foi escolhido para ser desenvolvido no presente trabalho, por ser extremamente atual e instigante, envolvendo um estudo sobre a sociedade do "superinformacionismo" em que vivemos. A temática é de aplicação genérica, pode servir a todos aqueles que pretendem que fatos passados não sejam eternamente disponibilizados a uma exploração eterna.

Quanto ao método, que consiste nos meios utilizados pelo autor para desenvolver a sua tese, no presente trabalho é o dedutivo. Observa-se assim o fenômeno de uma forma geral, qual seja o surgimento do direito ao esquecimento e analisam-se suas atribuições teóricas e práticas chegando a conclusões particulares na busca para resolver a problemática proposta.

A técnica utilizada para desenvolver a pesquisa foi a análise de casos concretos, legislação pátria, livros, artigos virtuais e citação de decisões judiciais nacionais e estrangeiras. A finalidade do trabalho é 
analisar a atuação do direito ao esquecimento em nosso sistema jurídico, verificando se este pode ser implantado com eficácia e sem prejuízo à liberdade de expressão e comunicação, uma vez que pode vir a limitar tais direitos.

\section{LIBERDADE DE EXPRESSÃO: INSTRUMENTO DA DEMOCRACIA}

O interesse pela preservação da liberdade de expressão, em seu sentido mais genérico de manifestar aquilo que se pensa, ou da liberdade de imprensa, aqui compreendidos meios televisivos, escritos, periódicos, radio difusores e virtuais, não é atual, e pode ser encontrado no texto da já citada Declaração de Direitos do Homem, de 1789.

Entretanto, apesar de hodiernamente estarmos imersos em um Estado, como bem sabemos, democrático de direitos, sabemos também que a história nem sempre se desenvolveu neste sentido. Mesmo após toda evolução normativa de garantias e direitos fundamentais, muitos foram os momentos em que estes foram sobrepujados.

Voltando os olhares para o cenário da história do Brasil, referente à privação da liberdade de informação, é pertinente pontuar como exemplo o Estado Novo. Getúlio Vargas, em 1937, suprimiu a Constituição de 1934 com um golpe e outorgou uma Carta Constitucional cujas características aproximavam-se do autoritarismo fascista. Neste período foram criados os Departamentos de Imprensa e Propaganda (DIP), uma política administrativa que funcionava como órgão de consulta e controle da polícia secreta do poder Executivo.

Outro momento histórico relevante ocorreu no período da República Militar. Após o golpe de 1964 nosso país convivia, mais uma vez, com a centralização do poder nas mãos do governo federal, que praticamente desfazia os modelos de tripartição dos poderes. A im- prensa foi novamente alvo de severa censura, e jornais como O Globo, a Tribuna da Imprensa e o Jornal do Brasil foram ocupados (COSTA; MELLO, 1999, p. 319).

Em 1967 foi editada a Lei de Imprensa (Lei $n^{0}$ 5.250/67), que estabelecia limites acerca das publicações e expressões a serem postas em circulação. Tais diretrizes legais foram responsáveis por diversas manifestações sociais contra a censura, o que desencadeou seu enrijecimento por meio da edição, em 1968, do Ato Constitucional $n^{0} 5$. Esse documento dava ao presidente da república respaldo legal para prática de arbitrariedades que colocavam em cheque vários direitos fundamentais. Dentre elas estavam o cancelamento de habeas corpus, cassação de direitos políticos e endurecimento dos atos de censura da imprensa e manifestação do pensamento, dentre outros.

Dessa forma, percebe-se que nas experiências ditatoriais do nosso País (como em todos os países) a liberdade de imprensa foi tratada como principal ameaça do sistema, o que demonstra a incompatibilidade entre ambos. Utilizando o raciocínio diametralmente oposto, concluímos ser a liberdade de informação inseparável aliada do Estado Democrático.

Isto porque a imprensa abrange duas esferas do direito à informação: o direito de ser informado e o direito de informar. Com isso, é instrumento viabilizador da participação popular na vida política do Estado, trazendo conhecimento e voz ao cidadão, permitindo a instauração de um sistema transparente e a respectiva expressão da opinião pública.

A Constituição Federal de 1988, dentre todas do Brasil, foi a que conferiu maior legitimidade popular, instituindo uma democracia liberal pautada nos ideais de justiça, solidariedade, igualdade e exercício de direitos sociais e individuais, sendo o decisivo ponto de ruptura com a ditadura.

Foi esta Constituição que instituiu, em seu preâmbulo, o Estado Democrático, assegurando valores de 
uma sociedade fraterna, pluralista, harmônica, livre de preconceitos e discriminações. A Constituição de 1988 fundou suas bases em princípios democráticos e garantiu a defesa de interesses individuais e coletivos. Nela, há o inédito reconhecimento dos direitos fundamentais num texto constitucional brasileiro, o que clamava instrumentos de proteção aos mesmos (LENZA, 2010, p. 119).

Tanto é assim que foi sob sua égide que a Lei de Imprensa foi afastada de nosso ordenamento jurídico através da ADPF 130. Apesar de alguns ministros defenderem a revogação parcial da lei, o argumento do relator, ministro Carlos Ayres Britto, prevaleceu.

Nele, o ministro defendia que a democracia seria inseparável da liberdade de expressão, e que uma lei editada em período de exceção institucional com o objetivo de cercear a liberdade de imprensa seria totalmente incompatível com o novo sistema democrático, conflitando-se irremediavelmente com os princípios da Constituição de 1988. Por outro lado, toda a matéria referente a direito de resposta, indenização ou responsabilização já havia sido descrita no texto constitucional, motivo pelo qual a vigência da lei, ainda que parcial, nenhum sentido fazia.

Interessante, e de fundamental importância para o presente trabalho, é apontar o único voto pela total improcedência da ADPF 130, do ministro Marco Aurélio, que defendia ser de competência do Congresso Nacional, enquanto representantes do povo, editar de uma nova lei que substituísse a Lei de Imprensa, adequando-a aos padrões democráticos. Isto porque, segundo o ministro, evitar-se-ia o vácuo legislativo sobre a mídia, que devido à grande influência que exerce na sociedade brasileira não poderia atuar a par de quaisquer limites.

A liberdade, em si, pode ter diversos desdobramentos: liberdade de locomoção, opinião, manifestação, crença, informação, expressão, pensamento etc. A censura ditatorial soube restringir, ainda que indiretamen- te, todas elas. O processo de redemocratização do Brasil, encabeçado pelos valores trazidos na Constituição de 1988, permitiu que o real panorama político-social do país fosse levado ao conhecimento do cidadão brasileiro, ao passo em que este poderia expressar-se livremente.

\section{PRINCIPAIS ASPECTOS DOS DIREITOS DA PERSONALIDADE}

Os desdobramentos acerca dos direitos da personalidade requerem prévio, ainda que breve, apontamento sobre a dignidade da pessoa humana, que, para Schreiber (2013, p. 7), seria o “valor-síntese que reúne as esferas essenciais de desenvolvimento e realização da pessoa humana”, sendo ela o principal objeto de tutela dos direitos da personalidade.

O mesmo autor faz uma sintética e elucidativa distinção sobre as terminologias de direitos humanos, direitos fundamentais e direitos da personalidade. São conceitos que abrangem peculiaridades divergentes, embora possuam em comum a finalidade última de proteção à dignidade da pessoa humana. Assim, leciona que os direitos humanos possuem um caráter internacional, independem até mesmo das regras internas dos Estados soberanos, sendo estes inerentes, apenas, à condição humana.

Já os direitos fundamentais seriam os direitos humanos positivados em texto constitucional, o que refletiria a proteção do homem em face do direito público, das ações estatais. Os direitos da personalidade, por fim, se referem aos atributos humanos merecedores de proteção na esfera privada, muito embora encontrem guarida, também, tanto no âmbito público, constitucional e até mesmo internacional.

Conforme já mencionado, os direitos da personalidade surgem como uma forma de proteger o homem não só dos desmandos e abusos cometidos pelo Estado, mas também por outros cidadãos, e até mesmo da vontade de seu próprio titular, conceituados como direitos que não se destacam de seus detentores (RODRIGUES, 2007, p. 61). 
Importante citar que a positivação dos direitos da personalidade não possui o condão de limitá-los. Isto porque, enquanto instrumento de defesa da dignidade da pessoa humana, podem se deparar com situações inéditas, inerentes à complexidade humana, devendo mesmo assim preservar cada uma delas. Dessa forma, tomando como exemplo nosso ordenamento jurídico, temos tanto no Código Civil quanto na Constituição, um rol destes direitos, mas que não é taxativo.

Diante da necessidade de invocar qualquer direito da personalidade não descrito em nenhum diploma legal, o fundamento é extraído do chamado "dever geral de tutela da dignidade da pessoa humana", constante no inciso III do artigo $1^{\circ}$ da Constituição Federal. 0 enunciado 274 da IV Jornada de Direito Civil, ratifica tal entendimento, confirmando ainda a ideia de não taxatividade de tais direitos, ao dispor que "os direitos da personalidade, regulados de maneira não exaustiva pelo CC, são expressões da cláusula geral de tutela da pessoa humana, contida no art. $1^{\circ}$, III, da CF (princípio da dignidade da pessoa humana)".

Na continuidade do trabalho, teremos a oportunidade de discorrer sobre o direito à imagem e à vida privada em face à atividade midiática desenvolvida pela imprensa e demais meios de comunicação. De fato, é antigo o confronto entre liberdade de informação e privacidade, que ainda gera discussões, movimentações judiciais e administrativas, além de inúmeros estudos e posicionamentos doutrinários. Entretanto, abordaremos o tema sob o enfoque de um novo instrumento em nosso ordenamento jurídico, qual seja, o direito ao esquecimento.

\section{A INTRODUÇÃO DO DIREITO AO ESQUECIMENTO NO ORDENAMENTO JURÍDICO BRASILEIRO}

Neste ponto do trabalho nos debruçaremos sobre as primeiras manifestações de reconhecimento e aplicabilidade do direito ao esquecimento em nosso ordenamento jurídico. De início, abordaremos a VI Jornada de Direito Civil que, ao aprovar o enunciado $n^{0} 531$, inseriu-o no rol de direitos da personalidade.

Em seguida, faremos a análise de dois casos judiciais ocorridos no Superior Tribunal de Justiça, que pela primeira vez utilizou o direito ao esquecimento na solução do conflito entre liberdade de imprensa e direito a imagem. Considerando a ausência de leis e teses doutrinárias sobre o tema no Brasil, destacase a importância do presente tópico, que nos permitirá acompanhar o nascimento de um novo instrumento jurídico de proteção à dignidade humana em nosso país.

Nos dias 11 e 12 de março de 2013, na cidade de Brasília, aconteceu a VI Jornada de Direito Civil, organizada pelo Centro de Estudos Judiciário do Conselho de Justiça Federal. 0 evento aprovou 46 novos enunciados de Direito Civil e contou com a direção do ministro João Otávio Noronha, do Superior Tribunal de Justiça, além da participação de professores, juristas, advogados, membros do Ministério Público e magistrados de várias cidades do país.

Um dos enunciados aprovados foi o de número 531, que pode ser considerado o marco inicial do direito ao esquecimento no sistema jurídico brasileiro. 0 enunciado, proposto pelo promotor de Justiça no Rio de Janeiro, professor e doutor Guilherme Magalhães Martins, possui a seguinte redação: "a tutela da dignidade da pessoa humana na sociedade da informação inclui o direito ao esquecimento. Artigo 11 do Código Civil”.

Do próprio texto do enunciado podemos extrair aspectos importantes, como o fato de o direito ao esquecimento ser instrumento de tutela da dignidade da pessoa humana, importando sua inclusão no rol dos direitos da personalidade e sua estreita correlação com a atual sociedade informativa. É importante ressaltar que mesmo desprovidos de força normativa, os enunciados de Direito Civil possuem autoridade doutrinária, pois servem de referência interpretativa, compõem fundamentações judiciais e incitam estudos sobre o tema. 
Por meio dela, podemos perceber a principal preocupação dos juristas que elaboraram o enunciado, qual seja os danos provocados, atualmente, pela evolução dos meios de comunicação. Por isso o direito ao esquecimento é considerado ainda prematuro, pois sua razão de ser é um fato social igualmente recente. A tese vem, então, como um ponto de ponderação, uma forma de garantir que os meios de comunicação, por mais avançados que sejam, não se tornem um campo onde o direito e os princípios fundamentais sejam deixados de lado.

O tema, contudo, sofre severas críticas, basicamente por dois fatores: sua prematuridade, e sua contradição com a liberdade de imprensa/expressão. Muitos ainda encaram o direito ao esquecimento como o camuflado retorno da censura, que permitiria ao judiciário eliminar fatos marcantes da história da sociedade e, com isso, legitimar a perda da memória de um povo.

Os principais críticos estão entre os defensores dos meios de comunicação, é o caso do advogado Alexandre Fidalgo, patrono da Editora Abril, que acredita ser o direito ao esquecimento uma ameaça à história e ao próprio direito ao permitir a indiscriminada exclusão de fatos públicos. 0 advogado alerta que tal direito seria uma verdadeira afronta aos valores da Constituição Federal do Brasil positivados em 1988, defendendo que o tempo não pode ser capaz de tornar uma notícia dantes lícita em ilícita.

Em contrapartida, trazemos o posicionamento do desembargador federal do Tribunal Regional Federal da $5^{a}$ Região, Rogério de Meneses Fialho Moreira, coordenador da Comissão da Parte Geral do Código Civil durante a VI Jornada, que em entrevista à revista eletrônica Brasília Em Dia afirmou o seguinte:

Quanto a colocar em risco a história, há evidente exagero na afirmação. [...] Esse direito, que estaria implícito na regra legal que assegura a proteção da intimidade, da imagem e da vida privada, bem como no princípio de proteção à dignidade da pessoa humana, garantiria apenas a possibilidade de discutir o uso que é dado aos eventos pretéritos.
O que o desembargador esclarece é que não se trata de uma chance de apagar a história, mas de resguardar determinados fatos do uso exacerbado da mídia. 0 que se busca, como pontua, é legitimar a discussão acerca da utilização de fatos que pretendem ser esquecidos, e não sua imediata exclusão. Entretanto, frisa que alguns juristas, nos quais se enquadra, pretendiam aprovar o enunciado após maior amadurecimento do tema na doutrina.

Continuando a análise do surgimento do direito ao esquecimento em nosso ordenamento jurídico, é imperioso que nos debrucemos sobre os dois primeiros julgados do país que aplicaram a tese. Trata-se de dois recursos especiais com o mesmo polo passivo, qual seja a emissora TV Globo. 0 ministro Luis Felipe Salomão, relator de ambos os recursos, construiu seu voto com fundamentos de direito comparado e precedentes da corte que formalizaram indispensável fonte de estudo da matéria.

No primeiro caso, o Recurso Especial n ${ }^{0}$.334.097/ $\mathrm{RJ}$, o requerente procurava ser indenizado em danos morais pela exibição não autorizada de uma reportagem que associava seu nome ao crime conhecido como "a Chacina na Candelária”, ocorrido em 1993 no Rio de Janeiro.

A reportagem seria levada ao ar pela emissora TV Globo Ltda., no programa Linha Direta - Justiça, que fazia a restituição de crimes e relatava os fatos dele decorrentes. De fato, o autor da ação havia sido processado pelo crime, mas fora absolvido por unanimidade do Conselho de Sentença no júri.

O documentário foi ao ar mesmo sem anuência do autor, relatando os fatos e indicando o nome deste, fazendo constar sua absolvição, o que não teve o condão, entretanto, de impedir a onda de desconfiança e ódio que fora reacesa na comunidade em que vivia. Em virtude disso, após tantos anos, a sociedade o encarava como "chacinador" outra vez, e o requerente viu a si mesmo e sua família serem alvo de ameaças e in- 
júrias por um fato de sua vida que já havia superado há anos, tendo inclusive que vender seus bens e se mudar.

O autor obteve a procedência do pedido de indenização por danos morais na instância ordinária, tendo sido, o recurso especial, interposto pela ré. Em suas razões, a emissora alegou inexistência do dever de indenizar por não haver em sua conduta nenhum caráter ilícito.

Em seu voto, Salomão entendeu que o conflito entre os valores fundamentais resguardados pela Constituição de 1988 (liberdade de imprensa e direitos da personalidade) merecia uma análise ponderada e razoável, capaz de identificar qual deles merecia prevalecer sobre o outro, como a já citada técnica de "sopesamento" proposta por Alexy. O cerne da discussão judicial não era a exibição do documentário sobre a chacina ocorrida no Rio de Janeiro, fato que sem dúvida entrou para a história do povo, mas apenas a utilização da imagem do autor e sua menção como um dos envolvidos no crime.

Relevante pontuar, neste momento, que o direito ao esquecimento não é sinônimo de direito ao segredo, que seria, segundo Nucci (2005, p. 610), “todo assunto ou fato que não deva ser divulgado, tornado público ou conhecido de pessoas não autorizadas”. Enquanto o direito ao segredo busca impedir que determinados fatos tornem-se públicos, o direito ao esquecimento pretende tutelar os fatos que já se tornaram públicos de novas explorações. 0 recurso especial, impetrado pela emissora de televisão, teve seu provimento negado por unanimidade, mantendo a decisão da instância ordinária em indenizar o recorrido no valor de $\mathrm{R} \$ 50.000,00$ (cinquenta mil reais) a título de danos morais.

Quanto ao segundo julgado, apesar de ter o núcleo semelhante ao anterior, as diretrizes do caso concreto conduziram a um julgamento de resultado diferente. Trata-se do Recurso Especial no $1.335 .153 / R J$, envolvendo a imagem e memória de uma mulher chamada Aida Curi, vítima de um trágico homicídio em 1958, que ganhou repercussão nacional à época.
Os autores da ação são os únicos irmãos vivos da mulher, e pretendem indenização por danos morais pelo fato de o mesmo programa de televisão (Linha Direta - Justiça), a par da advertência em sentido contrário, ter retratado o crime, com indicações da vida, detalhes da morte e pós-morte de Aida, o que fez com que a família revivesse outra vez a dor e o sofrimento já experimentado.

Diferente do caso anterior, o julgamento na instância ordinária determinou a improcedência dos pedidos formulados, sendo o recurso especial, no entanto, interposto pelos autores. As razões apresentadas pela emissora, contudo, foram bem semelhantes àquelas anteriormente citadas, que recaiam sobre a ampla publicidade e exploração conferida ao fato, que era abordado de forma recorrente em documentários, noticiários e até mesmo centros acadêmicos. Da mesma forma, buscava a inexistência do dever de indenizar em virtude de não haver qualquer ilicitude em sua conduta, afirmando a ré que apenas cumpria sua função social de informar, sem qualquer abuso ou desproporcionalidade.

Entretanto, o ministro pontua que o crime em questão, por sua grande repercussão nacional, incorporou-se ao domínio público e se tornou elemento histórico. A isso, soma-se a sua natureza trágica e o vínculo de sua narrativa à indicação da figura do ofendido, de modo que não se pode retratar o caso Aida Curi, sem citar a própria Aida Curi, pois são crimes onde o ofendido, infelizmente, seria sua característica marcante.

Para fundamentar a não concessão do pedido de indenização por danos morais, Luis Felipe Salomão faz uma interessante reflexão sobre os efeitos do tempo. Nesse momento, aduz que na mesma medida em que o tempo é responsável pela aquisição de um direito ao esquecimento, também é responsável por minimizar a dor e o sofrimento decorrente do confronto com certos acontecimentos passados. Sendo assim, considerando que à época da exibição do programa já havia se passado 50 anos da ocorrência do fato, há de 
se cogitar que o abalo emocional da família em revê-lo está minimizado, não possuindo mais o condão de limitar a atuação da imprensa.

Este segundo julgado ainda nos traz uma importante reflexão sobre o resultado da ponderação de valores utilizada. Relembrando as críticas direcionadas ao direito ao esquecimento, vimos que recaem principalmente na possível ameaça à história e à liberdade de imprensa. Note-se que no caso de Aida Curi, a corte do Superior Tribunal de Justiça, mesmo com fortes argumentos para defender a memória e a imagem da vítima de um crime bárbaro, entendeu que o tempo foi capaz de diminuir os efeitos de seu impacto, fazendo prevalecer a atividade jornalística em debater o fato, que faz parte da história e cuja narrativa não apresentou qualquer exorbitância.

\section{LIBERDADE DE EXPRESSÃO E DIREITOS DA PERSONALIDADE: NOVOS CONTORNOS DE UM ANTIGO CONFLITO}

Ultrapassada a análise do surgimento e da solidificação do direito de ser esquecido, propomos agora uma discussão sobre as novas delineações do antigo embate entre a atuação da mídia e dos demais meios de comunicação e a preservação de direitos como a honra, privacidade e a imagem. Aqui, pretendemos esclarecer a possibilidade e viabilidade de estabelecer diretrizes normativas que resguardem os meios de comunicação de provocar abusos ao mais íntimo do pulsar humano, refletindo sobre a evolução do Direito frente às novas demandas sociais.

Antes de adentrarmos a sistemática do impasse, nos cabe fazer um breve e retrospectivo apanhado sobre sua razão de ser. A Constituição Federal de 1988 reserva seu artigo $5^{\circ}$ para tratar dos direitos e garantias de caráter fundamental. Em seu inciso IV, defende a liberdade de manifestação, o inciso XIV assegura, por outro lado, 0 acesso à informação. Ainda em atenção a este artigo, o inciso IX dispõe que as expressões de atividades intelectuais e de comunicação estarão livres de censura ou licença, já o inciso subsequente descreve a inviolabilidade da honra, intimidade, vida privada e imagem das pessoas.

Este, como já visto em linhas anteriores, é o principal centro de conflito entre a liberdade de imprensa e os direitos da personalidade: o mesmo patamar constitucional de ambos, sempre invocado em desfavor do outro. Entretanto, também, já salientamos que apesar do caráter essencial e intrínseco ao ser humano, tais direitos não são absolutos.

Sobre este aspecto, no caso da liberdade de expressão, é pertinente apontarmos o raciocínio de Mendes (2007, p. 357) que, ao interpretar o artigo 220 da Constituição, pontua a existência de limites da liberdade de expressão no próprio texto constitucional.

Podemos observar que o primeiro parágrafo defende a liberdade de informação jornalística de possíveis embaraços trazidos por lei. Seria uma redação um tanto quanto genérica e abrangente não fosse pela sua parte final, de essencial interpretação e cuja observação recai o ensinamento do ministro. Nela, temos que a liberdade de imprensa é de fato objeto de grande proteção constitucional, porém desde que observe aspectos de direito fundamental, como aqueles citados acima.

Além dos parâmetros que podemos extrair do próprio texto constitucional, os casos apresentados no capítulo anterior demonstram a forte influência do Poder Judiciário no processo de "sopesamento" entre valores fundamentais. Como vimos no caso de Aida Curi, por exemplo, apesar de reconhecido o direito à imagem da vítima, o judiciário entendeu que a dor dos familiares ao reviver os fatos não tinha o condão de limitar a liberdade da imprensa naquele momento.

Perceba-se que quando tratamos da atividade profissional que envolve a confecção, circulação e publicação da notícia, há uma maior facilidade em es- 
tabelecer normas e diretrizes, seja por meio da interpretação de leis ou demandas judiciais. A mesma facilidade não se verifica ao estabelecimento de regras, limites ou diretrizes no ambiente virtual que, como já dito, não encontra limites de qualquer natureza.

Sabemos que o direito, enquanto instrumento regulador das relações sociais, deve sempre estar atento às mudanças que ocorrem na sociedade, desenvolvendo mecanismos hábeis a acompanhá-las. Com isso, precisa oferecer resposta às mais variadas formas de ofensa, abuso ou litígio, não importa quem são os sujeitos envolvidos, nem o espaço onde ocorreram.

O que notamos, atualmente, é um descompasso entre o alcance da norma jurídica e das possibilidades conflituosas oferecidas no ambiente da internet. A praticidade e efemeridade da rede causa a impressão de que as responsabilidades pelas ações ali praticadas não existem, ou são imensuráveis, o que a torna ainda mais atrativa àqueles que pretendem usá-la para fins ilícitos.

Dessa forma, notamos a necessidade da construção de um "ciberdireito" capaz de criar normas reguladoras que efetivamente possam acompanhar a atitude dos que lidam com a internet, no fito de impedir que se torne um meio hábil a atingir direitos e princípios de caráter fundamental.

Não se pode desprezar, contudo, a existência de desafios de índole técnica, que devem ser superados pelos juristas para que tais instrumentos normativos possuam efetividade. Com isso, deve o jurista conhecer a área de sua atuação para estabelecer normas correspondentes e eficientes, o que não se pode permitir é que a estrutura virtual sirva de impasse à atuação do direito. Para corroborar tal raciocínio, colacionamos as palavras de Marco Aurélio Greco:

[...] diante destas novas realidades, cumpre evitar duas posturas igualmente inadequadas em se tratando desta novidade que são os sites da internet: uma é repelir a aplicação dos conceitos que foram construídos no âmbito do Direito como se a realidade fosse totalmente diferente e eles fossem absolutamente inadequados. Não há dúvida que a novidade é manifesta e que esta realidade virtual escapa do padrão que baseou a disciplina normativa dos últimos séculos. Por isso pode-se dizer que os conceitos clássicos estão em crise, pois não são suficiententemente operativos para regular a realidade atual, mas isto não significa que os standards que os informam e os valores e finalidades que visam não sejam semelhantes aos que devem encontrar aplicação no âmbito da internet (boa-fé, lisura de comportamento, etc...) Outra postura igualmente simplista é pretender considerar que os conceitos construídos a partir de um mundo material são automaticamente transplantáveis para o âmbito da internet. Exageramos em sentido oposto, pois, assim como é fato que existem conceitos, institutos, figuras e normas que podem ter aplicação no mundo virtual, também é fato que este apresenta características absolutamente novas que não são captadas pelas normas existentes. A conclusão que daí decorre é que há todo um conjunto de situações novas que exige um esforço de todos os estudiosos do Direito, no sentido de buscar uma disciplina que seja compatível com as características técnicas e operacionais da informática e que conduza a uma nova conformação de institutos jurídicos existentes e ao nascimento de outros novos, seja quanto aos objetos das relações jurídicas, seja quanto ao seu valor ou conteúdo. (GRECO, 2001, p. 313-314).

Não nos parece outro o direcionamento de nosso ordenamento jurídico, pois no dia 23 de abril de 2014 foi sancionada a Lei 12.965/14, conhecida como Marco Civil da Internet. Entre os principais temas abrangidos na lei, estão a privacidade dos usuários, a liberdade de expressão e a retirada de conteúdo do ar.

Com atenção aos artigos desta norma, notamos que a preocupação do legislador é garantir ao usuário da internet os direitos já inseridos na Constituição, com a peculiaridade do ambiente em que se enquadra. As disposições sobre privacidade, por exemplo, proíbem empresas de Internet de repassarem os dados de seus clientes a terceiros, evitando abordagens publicitárias indesejáveis.

A lei também cria diretrizes para que determinados conteúdos sejam retirados do ar, vez que não havia 
qualquer regramento específico sobre o tema. Agora, a retirada do conteúdo da rede pode ser feita, desde que, e somente se, haja ordem judicial neste sentido.

Apesar de a nova lei de disposições virtuais não trazer em seu bojo a terminologia relacionada ao direito ao esquecimento, é perceptível que seus fundamentos ali se encontram. É o direito ao esquecimento que respalda o pedido judicial de retirada de informações da rede que abusivamente exploram fatos que já mereçam ser esquecidos.

Vale lembrar que o direito ao esquecimento tem sua justificativa no direito brasileiro, exatamente pelo avanço dos meios de comunicação, o que sem dúvida inclui o ambiente virtual.

Como um recente exemplo de aplicação direta do direito ao esquecimento, temos uma decisão do Tribunal de Justiça da União Europeia que condenou o buscador do Google a retirar do ar um link que prejudicava a imagem do autor da ação. No caso, o requerente é um advogado que, em 1998, teve dois anúncios de leilão de imóveis de sua propriedade por dívidas à Seguridade Social.

O autor percebeu que mesmo após tantos anos, quando colocava seu nome no provedor de busca, surgia a imediata referência com os leilões e a dívida que, uma vez paga há aproximadamente dez anos, não possuía mais qualquer relevância.

O Tribunal de Justiça da União Europeia entendeu que o Google tem responsabilidade pelos dados que indexa, e exigiu que ele disponibilizasse meios de atender diretamente a solicitação de europeus que pretendam ver seus nomes e sobrenomes desvinculados de provedor. Assim, em maio de 2014 o Google lançou um formulário que deveria ser preenchido pelo interessado "a ser esquecido".

0 advogado do requerente, Joaquín Muñoz explicou que mesmo nas situações em que a fonte que publicou o conteúdo não o retirar do ar, e até nas ocasi- ões onde a informação for lícita, a indexação não pode ser feita se a pessoa envolvida sentir-se prejudicada, uma vez que é dele o direito de decidir quem trata ou não seus dados. Frise-se que no caso, o que está se permitindo é a retirada de determinado site do indexador de busca do Google, e não da internet como um todo.

Esta decisão provocou muita discussão e foi importante aliada do direito ao esquecimento ao estabelecer, a partir de um caso concreto, diretrizes sólidas para sua aplicabilidade, reconhecendo a irrelevância atual da notícia e o prejuízo que esta traria ao autor do caso.

\section{CONCLUSÃO}

Em antigos casos judiciais onde o aplicador do direito precisava inclinar-se pela prevalência de um ou outro valor fundamental entre a liberdade de imprensa e os direitos da personalidade, os pedidos fundavam-se basicamente pela ilicitude ou inverdade da notícia, o que obviamente pendia para uma decisão favorável ao segundo direito. Atualmente nos deparamos justamente com notícias e divulgações que, ainda que verídicas e lícitas, não devem sofrer exploração eterna, sob pena de atingirem gravemente alguns direitos fundamentais personalíssimos.

Por isso o direito ao esquecimento surge, e traz consigo um aparato de orientações que não permite, ao contrário da crítica ao seu redor, que cultura e história sejam ameaçadas. Para aplicar este direito sem cometer leviandades ou injustiças, o julgador precisa ponderar de forma cautelosa todas as vertentes apresentadas pelo caso concreto e permitidas pelo ordenamento jurídico.

Assim como já dito reiteradas vezes ao longo do trabalho, também o direito ao esquecimento não é absoluto. Sua utilização depende desta criteriosa ponderação de valores que se utilizará de critérios de razoabilidade e proporcionalidade. Com o direito ao esquecimento não se pretende legitimar a exclusão 
de fatos dos registros históricos, sejam físicos ou virtuais, nem que a livre manifestação esteja sob o enfoque de nova censura, apenas conferir a possibilidade de se discutir a utilização que é dada a determinados fatos que já foram devidamente explorados à época em que ocorreram.

Sendo assim, deve ser levado em consideração, dentre vários fatores, o interesse público atual no fato divulgado, ou sua importância histórica, que deve persistir para que não caiba o direito ao esquecimento. Ainda, o efetivo dano provocado na vítima da superexposição, que também precisa ser levado em consideração quando confrontado com a liberdade de expressão.

A efetivação do direito ao esquecimento ainda possui um terreno deveras incerto, mas suas bases, conforme discorremos ao longo do trabalho, caminham cada vez mais para sua solidificação.

\section{REFERÊNCIAS}

ALEXY, Robert. Teoria dos direitos fundamentais. 2.ed. Trad. Virgílio Afonso da Silva. São Paulo: Malheiros, 2011.

ARAÚJO, Luiz Alberto David; NUNES JÚNIOR, Vidal Serrano. Curso de direito constitucional. 13.ed. São Paulo: Saraiva, 2009.

BLAINEY, Geofrey. Uma breve história do mundo. 2.ed. São Paulo: Fundamento Educacional, 2009.

BRASIL. Código Civil, de 10 de janeiro de 2002. Disponível em: <http://www.planalto.gov.br/ ccivil_03/leis/2002//10406.htm>. Acesso em: 3 nov. 2014.

\section{BRASIL. Constituição Federal de 5 de outubro de}

1988. Disponível em: <http://www.planalto.gov.br/ ccivil_03/constituicao/ConstituicaoCompilado.htm>. Acesso em: 28 out. 2014.
BRASIL. Lei 12.965, de 23 de abril de 2014. Disponível em: <http://www.planalto.gov.br/ ccivil_03/_ato2011-2014/2014/lei/l12965.htm>. Acesso em: 3 nov. 2014.

\section{BRASIL. Superior Tribunal de Justiça. Recurso}

Especial 1335.535/RJ (2011/0057428-0). Relator: Luis Felipe Salomão. Julgado 28 de mai. 2013. Disponível em: <https://ww2.stj.jus.br/processo/ revista/documento/mediado/?componente=ITA\&sequ encial $=1237428$ \&num_registro $=201100574280 \& d a t$ $a=20130910 \&$ formato=PDF $>$. Acesso em 1 nov. 2014.

BRASIL. Superior Tribunal de Justiça. Recurso

Especial n0 1.334.097/RJ (2012/0144910-7). Relator: Luis Felipe Salomão. Julgado 28 de maio 2013. Disponível em: <https://ww2.stj.jus.br/processo/ revista/documento/mediado/?componente=ITA\&seque ncial=1239004\&num_registro $=201201449107 \& d a t a=$ $20130910 \&$ formato=PDF>. Acesso em: 1 nov. 2014.

BRASIL. Supremo Tribunal Federal. Supremo julga Lei de Imprensa incompatível com a Constituição Federal. Notícias STF. 2009. Disponível em: <http:// www.stf.jus.br/portal/cms/verNoticiaDetalhe. asp?idConteudo=107402>. Acesso em: 9 set. 2014 .

COSTA, Luís César Amad; MELLO, Leonel Itaussu A. História do Brasil. 11.ed. São Paulo: Scipione, 1999.

DINIZ, Maria Helena. Curso de Direito Civil

Brasileiro, volume 1: Teoria Geral do Direito Civil. 26.ed. Reformulada. São Paulo: Saraiva, 2009.

DIREITO ao esquecimento na sociedade da informação. Revista Brasília em Dia. Disponível em: <http://brasiliaemdia.com.br/component/ content/article/148-edicao-845/1578-direito-aoesquecimento-na-sociedade-da-informacao>. Acesso em: 23 out. 2014.

FRANÇA. Declaração dos Direitos do Homem e do Cidadão, 1789. Disponível em: <http://www. 
fd.unl.pt/docentes_docs/ma/mla_MA_19926.pdf>. Acesso em: 26 out. 2014.

GAGLIANO, Pablo Stolze; PAMPLONA FILHO, Rodolfo. Novo curso de direito civil: parte geral. São Paulo: Saraiva, 2002.

GOOGLE lança formulário para apagar dados pessoais de usuários europeus. Revista Época, maio 2014. Disponível em: <http://epoca.globo. com/vida/vida-util/tecnologia/noticia/2014/05/ google-lanca-formulario-para-bapagar-dadosbpessoais-de-usuarios-europeus.html>. Acesso em: 3 nov. 2014.

GRECO, Marco Aurelio. Estabelecimento tributário e sites na internet. Coord. Newton de Lucca e Adalberto Simão Filho. Direito \& Internet: aspectos jurídicos relevantes. Edipro, 2001.

\section{LENZA, Pedro. Direito constitucional}

esquematizado. 14.ed. São Paulo: Saraiva, 2010.

MARCO Civil da Internet entra em vigor. Marco Civil da Internet: seus direitos e deveres em discussão. Cultura Digital, jun. 2014. Disponível em: <http://culturadigital.br/ marcocivil/2014/06/23/marco-civil-da-internetentra-em-vigor/>. Acesso em: 3 nov. 2014.

MARTINS, Ives Gandra da; MENDES, Gilmar Ferreira; NASCIMENTO, Carlos Valder do. Tratado de Direito Constitucional. São Paulo: Saraiva, 2007.

NUCCl, Guilherme de Souza. Código Penal Comentado. 5.ed. São Paulo: Revista dos Tribunais, 2005.

OST, François. 0 tempo do direito. Trad. Élcio Fernandes. Bauru, São Paulo: Edusc, 2005.

PINHO, Rodrigo César Rebello. Teoria geral da constituição e direitos fundamentais. 4.ed. São Paulo: Saraiva, 2003.

RODRIGUES, Silvio. Direito Civil: parte geral. 34.ed. São Paulo: Saraiva, 2007.

SCHREIBER, Anderson. Direitos da Personalidade. 2.ed. São Paulo: Atlas, 2013.

SILVA, José Afonso da. Curso de direito constitucional positivo. 27.ed. São Paulo: Malheiros Editores, 2006. 
Data da submissão: 06 de julho de 2015

Avaliado em: 7 de outubro de 2015 (Avaliador A)

Avaliado em: 23 de janeiro de 2016 (Avaliador B) Aceito em: 28 de janeiro de 2016

1. Doutorando em Direito pela Mackenzie; Mestre em direito pela UFS; Professor universitário da UNIT e advogado. E-mail: contato@diogocalasans.com 2. Bacharel em direito pela UNIT. E-mail: contato@diogocalasans.com 